\title{
Modelling agent activity and diagnostics of agency professional competencies
}

\author{
Nadezhda N. Pokrovskaia \\ Department of Advertising and Public Relations \\ Peter the Great Saint-Petersburg Polytechnic University \\ St. Petersburg, Russia \\ nnp@spbstu.ru,nnp@europe.com
}

\author{
Denis A. Fedorov \\ Department of Advertising and Public Relations \\ Herzen State Pedagogical University of Russia \\ St. Petersburg, Russia \\ piarman@gmail.com
}

\author{
Dmitry V. Golohvastov \\ Department of Human Resources Management \\ $\mathrm{StPb}$ University of Management technologies \& Economics \\ St. Petersburg, Russia \\ lel@bk.ru
}

\begin{abstract}
Expansion of Digital tools of economic activity reveal the role of the humans within the business processes. The growth of aggregators as a business model that automates the agency activity causes interest in the analysis of the content of professional agency activity and the identification of the specifics that differentiate the work of the agent from the algorithms of intellectual data processing. Under agency activities we consider the professions of doctors, lawyers, realtors. The spread of telemedicine, systems of normative legal documents and artificial intelligence, databases of offers and requests in the field of real estate, nevertheless, does not lead to the disappearance of these types of agents. On the contrary, the work of competent professionals in these areas is increasingly in demand. This means that the specific qualities and parameters of agency activity for today are not amenable to full algorithmization, i.e. it is possible to identify the specific agent competencies, which are more valuable than the processing of medical, legal information or real estate market data. The article examines the main components for constructing the model of the professional agency activity and provides an example of diagnosing the professional agent's competences in the digital economy.
\end{abstract}

Keywords - modelling, agent, professional diagnostics, agency compensations, digital economy.

\section{INTRODUCTION}

The information society and digital economy development leads to the emergence of new business models, a significant part of which relates directly to the field of information technology, data processing and intellectual analysis.

A superficial view of the content of agency activity leads to the conclusion that the profession of the agent in the digital economy has disappeared, giving way to intelligent data processing systems and selecting the most attractive options.

The paper represents an attempt to identify the factors that determine the specific competences of agency as a special type of professional activity, which allows us to distinguish the economic functions of professional information processing (as the core element of the agency) and the complementary tasks of building trust, motivation, moral support in decisionmaking and responsibility-taking.

Based on the analysis of agency competences, a model of the professional activity of the agent is proposed. In order to precise the content and context of implementation of the competencies, the material presents the results of a survey of representatives of two different groups of agency activity - the medical service and the real-estate transactions. The research helped to identify the concrete elements of the agency functions within the two observed industries and to discover the ontology of agency activity.

\section{INTELLIGENT SYSTEMS TO SUBSTITUTE AGENCY ACTIVITY ADVANTAGES AND LIMITATIONS}

Information society produces new specific activity which relates to the treatment of redundant data, to the mastering the excrescent knowledge. Agency as societal institutional answer to react to this new environment required the definition and research, but it was given, first of all, from the standpoint of the capital: the relations between the investors and managers were examined to give advices to the owners about controlling the business.

The agency as a specific activity and societal institution is analyzed in the works on institutional [1] or conceptual [2] scientists. These works presented a wide bulk of approaches for the search of solutions for agency conflicts in the field of management and politics.

The agency studied a phenomenon of economics, but the research gap consists in the understanding of its essential features that are revealed, required and institutionalised within the information society and digital economy. The new context allows researchers to make in evidence of the specific agency competencies required by the new societal structure. 


\section{A. Agency, collective regulations and institutional traps}

The agency helps in the case of asymmetry of information, when one of the actors knows less than the other(s), and when the efforts to increase the knowledge about a situation or a sector are too costly.

The economic, financial and management science made attempts to propose endogenous solutions for the conflict of interests of agent and principal - by introducing the principal's purposes into the agent's list of objectives: if agents are acting in accordance with their own interests, changing incentives to redirect these interests may be beneficial for principals. But, the formal contracting of these incentivizing tools produces also the opportunist behaviour or other unintended consequences, such as moral hazard or adverse selection.

The efficiency of the agency tools is grounded in the cultural inertia, e.g. the trust and reputation, based on previous experience, presented in recommendations or shared past, e.g., previous joint projects or co-lived events.

The correct behaviour of the agent with targeted results for the principal (e.g., the patient' recovery after the medical cure) provokes the further demand for the agent's services and the future increase of her/his income (wage for the service). Thus the spontaneous market develops the mechanism of collective regulation for the industrial wisdom with the emergency of the institution of reputation which creates incentives for efficient personal behaviour [3]. From this point of view, the agency represents a market mechanism to overcome the institutional traps due to the specific competencies of agents as competent actors - and the digital economy has new tools to solve this task.

\section{B. Big data: the volume of information processing}

The most important advantage of intelligent information systems is the ability to process large amounts of data that are inaccessible to people, for example, millions of calls, feedback comments, requests. In the conditions of standard inquiries, for example, hotel reservations, information technologies have an undeniable advantage over people with the big data treatment.

However, in a unique situation where a request or proposal is not ordinary, not amenable to formal standardization, or is extracted meaningfully from an array of similar data, in this case machine learning, in the first stages, refers to human intervention for proper classification within the created model or for modification criteria for evaluation and for modelling the new ontological specifics [4]. Probably, the development of artificial intelligence will solve this problem of nonstandard, individualized tasks.

\section{Objectivity of results}

Another important advantage of automated models of information processing, classification and choice of options, is their objectivity, soundness and validity. However, breaches of validity are also possible as a result of the following typical factors:
- advertising (in the search engine the first lines show paid links to the entered set of words, in the businessmodel of selling words, targeted communicative tools shift the intellectual results for the profit-driven business purposes),

- lack of selection criteria (for example, there are not enough fields or answers' options in the medical questionnaire to fill in for diagnostics),

- inadequacy of the model or ontology, the subject area (for example, in the legal sphere, the applicant's problem may lie in the field of tax law rather than labour law).

\section{Spatial-temporal relevance}

An essential advantage of information and telecommunication technologies and intelligent systems implemented in agency activity is the application of knowledge at a specific punctual place in space and time. In the case of medical intervention, the factor of locality and timeliness is especially noticeable: medical care must be rendered on the right moment and in the right place. If it is a question of remote areas, the physical distance makes timely medical help problematic, in this regard, telemedicine and automation can largely be a solution to the issue of providing assistance correctly on time. Thus, bracelets for the analysis of blood for diabetics with insulin injections, which are introduced automatically in the case of a sharp decrease in the insulin content in the patient's blood, successfully illustrate the preference for information technology in the medical field.

Similar examples can be given in other subject areas, where the main content of the value chain is agency activity, for example, the need for legal assistance to address issues of dismissal of a pregnant woman or in the help of a real estate agent to solve a housing problem, when it comes to choosing a block or a house with special environmental properties, odours from a landfill, a wind chill or a view from a window on the wall of the neighbour house, or selling industrial property that annually loses a part of its value due to the destruction of the infrastructure and the buildings themselves.

Thus, if information support is urgently needed, then often intelligent systems for analysis and support of decisions, multi-criteria choice and transactions can be much more effective than solutions attracting human resources.

This raises the problem of ensuring reliability of access to intelligent and automated systems and data sources, in particular, access to Internet space.

\section{E. Trust as a problem of aggregators and agents}

From the listed advantages of intellectual systems, it is evident that there is only a limited list of situations in which a human person acting as an agent can have advantages comparing with information technology and artificial intelligence. Almost all these advantages are based on the regulatory mechanisms and socio-psychological tools and methods [5], developed and institutionalized by society: 
- Psychologically, the interaction with her/his agent forces the principal (patient, client, employer), first of all, to decide whether she/he really wants to start the process and to achieve the results. This interaction helps to understand what she/he really plans to do or to acquire - interpersonal interaction plays a specific role as a catalyst for starting an action, and as a developer to determine whether the customer wants what she/he is trying to get. Socio-psychological characteristics of interpersonal interaction cause the client (principal) to express her/his intentions in a verbal form with intonations or gestures, or in any other form which would be understandable to the interlocutor, and for this purpose the client, for her/himself, explicitly clarifies the form and strength of her/his intention [6].

- From the point of view of the professional practice, the interaction with the agent allows the principal to relate her/his situation to other similar ones. If the intellectual system does not give "feedback" to the customer, then the doctor can say: "Don't worry, this is not a rash, it's a mild annoyance"; a lawyer can assess the degree of danger of dismissal from the point of view of the accumulated experience of conflicts solved and of the correlation between the labour market demand and supply; a real estate agent may propose to the client to agree to rent a lodging to a family with animals or children, taking into account the low level of demand or the drop in the rental rate on the local housing market.

- Finally, in the conversation with the agent, the principal finds out her/his degree of readiness to pass from the desires and plans to the action, which also reveals the measure in which the principal would like to share the burden of responsibility and the potential consequences of the decision with other actors, in this case, with the agent. In the case of medical services, often the principal has virtually no foundation (knowledge or experience) to make an informed decision, and relies on a doctor's advice to further obtain the desired result (for example, recovery health). At the same time, in conditions of complete or almost complete uncertainty, only a small part of individuals are able to make decisions and bear the risks of their potential consequences, this is the category of entrepreneurs, yet other people, because of psychological mechanisms of stability, prefer not to make decisions within uncertainty. Thus, the division of responsibility makes people "bolder" and forces them to act more willingly than in the absence of an agent.

Obviously, the division of responsibility is impossible without trust to the agent [5]. Confidential relationship and trust to the agent on the part of the principal is the basic reason for the formation of agency relations, since the agent performs not only the amount of work for the customer (client, patient, employer), but also the functions of initiating a transaction or launching a project, making a choice, making a decision, taking risks and bearing responsibility for the decision.
Aggregated portals, such as Airbnb, Booking.com etc., need a voluminous feedback system, which is structured by a set of different, mostly quantitative parameters to increase the degree of customer confidence in databases and selection of options. For the agent, it is enough to recall the referent, in some cases, even only one reputed person, because the reputation of the individual giving the agent a recommendation plays a significant (qualitative) role. On the one hand, a qualitative assessment saves transaction costs; on the other hand, it contributes to the formation of closer network links and structures of the relationships and reputations of different participants, clarifies their social capital.

In intellectual analytical systems, reputation can be taken into account on the basis of algorithmic club filtering, in which the recommendation (score, rank) is multiplied by the weight of the recommender or reviewer, this rank is based on the multi-criteria reputation assessment - a parameter in which the reputation of the referent is evaluated in many aspects, by areas and spheres of issues, for example, the opinion of an individual can be assessed as very significant in tax law and of the medium importance of housing law.

On this basis, we can propose to a) build a scheme for institutionalizing agency activity as a special form of socioeconomic professional activity in the digital economy, and b) determine the main agency competencies that determine the effectiveness of the agent's activity.

\section{INSTITUTIONALIZATION OF AGENCY ACTIVITIES AND EVALUATION OF AGENCY COMPETENCIES}

Modelling the professional activity of the agent is based on the functional-purpose scheme of the role of agency activity in the economy and society.

\section{A. Institutionalization of agency activities}

The principal invites the agent, in contrast to the employee or freelancer, to externalize some of her/his own functions, since it seems more expedient for the principal to outsource part of her/his tasks and transfer this part to another person. If socialization means interiorization, assimilation and adoption of social norms and values, the development of agency activity reflects the opposite process of externalization within the social world of modernity [7]: the principal seeks to bring "outside" and pass on to other entities a part of her/his own responsibility for the beginning, fulfilment and effective completion of some actions. First of all, this is due to competence, which in this case can be defined as the ability to act on the basis of accumulated knowledge and experience [8].

The institution of agency activity acts in society as a reaction to the overestimated necessity for making choices, especially in the society of consumption and saturated markets, and in assuming responsibility [9].

Thus, the emergence of agency relations, on the one hand, is based on the insufficient knowledge, uncertainty of motivation and unwillingness to assume the full responsibility of the principal, and, on the other hand, on the ability to form trustful relationships, the increase of experience and 
reputation, the developed emotional intelligence of the agent. The analysis of the emotional and motivational sphere is expected to become the subject of neural communications [10], but so far people are demonstrating a higher efficiency than machines.

This means that effective work of the agent requires both professional knowledge (and its constant updating, advanced training, attendance of conferences, seminars and various industry forums), as well as a whole range of personality features that ensure that the agent performs sociopsychological functions in the performance of professional agency activity.

It can be assumed that the personal interaction between the agent and the principal is a unique part of the agency's activity, the communication between two infinitely complex actors, seeking to use their strengths (for example, the patient is willing to use will power to perform prescribed exercises or procedures, and the physician is ready to take responsibility for the improvement or treatment of a patient's disease), so far, until today, this part is not reducible to action with the help of intellectual analytic systems and decision-making support.

Thus, the general ontological scheme of the professional activity of the agent can be represented in Fig. 1.

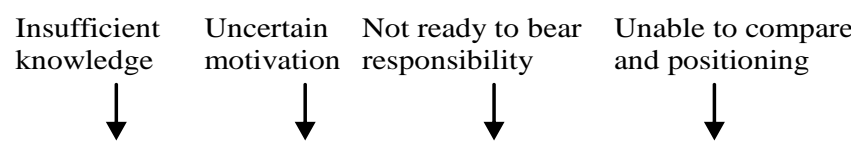

Choice to contract an agent better than an autonomous acting

The principal (customer, client, manager) satisfaction with the agency results - agency functions are fulfilled, if:

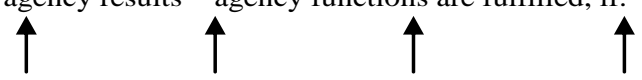

1. The agent provided structured information on clear selection criteria, demonstrated knowledge, experience and competence in her/his professional field

2 . The agent has understood and revealed the true motives for the principal, disclosed her/his desires, needs and expectations, clarified the intentions and costs of the principal's resources

3. Part of the responsibility for making a choice and a decision fell on the agent, which gave the principal a sense of sharing of burden of responsibility and a moral relief

4. The experience and awareness of the field' situation, demonstrated by the agent in her/his professional sphere, enabled the principal to better understand her/his own situation

Fig. 1. Ontological scheme of institutionalization of agency activity

If the business model of the aggregator successfully copes with the tasks of replenishment of insufficient knowledge or information, then the intellectual systems today are still not efficient in the process to bring this knowledge into action, i.e. the essence of agency activity is to clarify the motivation, to share the responsibility and to reframe, to compare, in a gentle, delicate and steady manner, the position a particular case of a specific client in the overall system of relations in a particular industry market or in a particular subject area.
To identify the specific agency competencies, a study was carried out in 2017 in Saint-Petersburg area. The free-lancers and employees performing agency functions, namely medical staff, doctors $(\mathrm{N}=29)$ and real estate agents, realtors $(\mathrm{N}=34)$ were surveyed.

The both groups were chosen with the principle of the snowball, the medical advisers were the employees of the public clinics $(\mathrm{N}=17)$ and private medical companies $(\mathrm{N}=12)$. Among the real-estate agents, the realtors functioning at freelance represent an important part of the sample $(\mathrm{N}=19)$, but several persons are also working as employees in (or co-operate with) private real-estate agencies $(\mathrm{N}=23)$, so, the number of "pure" freelancers among the respondents was only 11 , but in the sector of real-estate, no public organisations were examined, because there are no State or municipality owned agencies on Saint-Petersburg market in 2017. The sample includes 4 public clinics and 2 private medical companies, and 3 private real-estate agencies.

The assessments of key competences determining agent efficiency, according the opinions of the respondents, are given in Table 1:

TABLE I. KEY AGENCY COMPETENCIES OF MEDICAL SPECIALISTS AND REAL ESTATE AGENTS

\begin{tabular}{|l|c|c|}
\hline \multicolumn{1}{|c|}{ Competence } & Doctors & Realtors \\
\hline Professional knowledge & $100.0 \%$ & $91.2 \%$ \\
\hline Professional competence & $100.0 \%$ & $100.0 \%$ \\
\hline Willingness to take responsibility & $82.8 \%$ & $85.3 \%$ \\
\hline Emotional intelligence & $58.6 \%$ & $52.9 \%$ \\
\hline Ability to inspire confidence & $48.3 \%$ & $73.5 \%$ \\
\hline $\begin{array}{l}\text { Ability to identify motivation, interests and } \\
\text { limitations of the client }\end{array}$ & $37.9 \%$ & $55.9 \%$ \\
\hline Ability to stimulate to action & $34.5 \%$ & $47.1 \%$ \\
\hline $\begin{array}{l}\text { The ability to delicately but clearly show a } \\
\text { comparison of the situation with analogues }\end{array}$ & $13.8 \%$ & $23.5 \%$ \\
\hline
\end{tabular}

a. Compiled by the authors on the basis of the own empirical research

In the results obtained, the unanimity of all interviewed employees of medical institutions (doctors) and real estate agencies (agents, realtors) is noticeable in the commonly shared opinion that the agent must have professional competence for successful fulfilment of her or his professional activity (100.0\% in both groups).

But if $100.0 \%$ of doctors believe that this requires professional knowledge, only $91.2 \%$ of real estate agents agree on this, they rather rely on the experience and practice accumulated during the period of work in the industry. This is understandable: if the pharmaceutical business conducts significant experimental research, verifying and testing new drugs for bringing them to the market during periods of $R \& D$ from 12 to 15 years, if the medical methods need a long-term approbation [9], then the realtors rely on their own experience and the situation on the volatile real estate market.

At the same time, more than $80 \%$ of the respondents of both groups noted the importance of skill and willingness to share responsibility with the patient $(82.8 \%)$ or client $(85.3 \%)$, 
since both the doctor and the real estate agent act as trustees for the principal.

Proceeding from the obtained results, it is possible to draw conclusions about diagnostics of agency competences as personal qualities and as professional skills. In particular, if the stock of knowledge accumulated in the course of higher education is very important for doctors, for realtors the willingness to constantly learn and keep an open mindset for new trends and for individuals' needs is even more important. If the doctor relies more on her/his knowledge (100.0\%) and only $48.3 \%$ on the ability to inspire confidence in the relationship with the patient, then for a realtor the ability to form a trusting interaction is crucial, as it is assessed by $73.5 \%$ of the surveyed real estate agents. Finally, if the doctor can leave the right to decide and act to the patient to a greater extent $(34.5 \%$, only a third part of respondents think that they have to stimulate action), for almost half of the realtors (47.1\%), encouraging the client to act is an important functional characteristic of a successful agent.

Drawing on a specific model of professional agency activity and competence, it is important to note the purposes of such diagnosis. The analysis and model of the agency competence can be helpful in two essential directions - on the one hand, to define the tasks for a person in which a human being has undoubted advantages over a machine or artificial intelligence; on the other hand, the sense of modeling agency activity [4] consists precisely in the construction of algorithms that will allow one to expand the field of technological solutions of the agent's routine functions within the artificial intelligence.

\section{Conclusion}

The issues of professional agent diagnostics are hampered by a number of circumstances: the deeply personal nature of a number of traits, for example, the ability to inspire trust, the willingness to take responsibility for decisions made, and the volatility and uncertainty of the environment. The concerns of information processing today are largely transferred to intellectual analysis with intelligence systems, aggregating data and based on complex search and selection algorithms making multi-criteria choice.
At the same time, the person remains a significant layer of interpersonal interaction, which, for the time being, can not be transferred to aggregators either in the form of a feedback system, including club filtering, taking into account qualitative parameters of the applicant's reputation, or in the form of direct analysis data, which today are still sufficiently truncated.

The task of modelling agency activity in the future will be the construction of an algorithm for "magic" of interpersonal interaction and the fulfilment of the socio-psychological functions of the agent as a trustee of the principal.

\section{References}

[1] V. Polterovich, "Institutional traps: is there a way out?" Social Sciences, A Quarterly Journal of the Russian Academy of Sciences, vol. 36, 2005 , pp. $30-40$

[2] R. Beveridge, Ph. Koch, "The post-political trap? Reflections on politics, agency and the city", in Urban Studies, Vol. 54, issue 1, 2017, pp. 31-43.

[3] Tirole, J.A. Theory of Collective Reputations with Applications to the Persistence of Corruption and to Firm Quality. Paris: Institut d'Economie Industrielle, Toulouse, MIT and Ceras, 1993.

[4] M.Yu. Ababkova, N.N. Pokrovskaia, and I.R. Trostinskaya, "Neurotechnologies for knowledge transfer and experience communication", in Europ. Proc. of Social \& Behavioural Sciences (EpSBS), 2018, vol. XXXV, pp. 10-18.

[5] D.V. Golohvastov, N.N. Pokrovskaia, and S.O. Snisarenko, "Institutional Confidence and Economic Intelligence for the Performance at Macro and Micro Networks", in Proc. of 4th Int. Conf. on Management, Leadership and Governance ICMLG 2016. Reading, UK: Academic Conferences and Publishing International Limited, 2016, pp. 255-263.

[6] M. Polanyi, The Tacit Dimension. Chicago: University of Chicago Press, 1966.

[7] A. Giddens, Modernity and Self-Identity. Self and Society in the Late Modern Age. Cambridge: Polity Press, 1991

[8] I. Nonaka, and H. Takeuchi, The Knowledge-Creating Company: How Japanese Companies Create the Dynamics of Innovation. N.Y.: Oxford University press, 1995.

[9] J.-P. Garnier, "Rebuilding the R\&D Engine in Big Pharma", in Harvard Business review, May 2008, pp. 69-76.

[10] T. Davenport, and J. Short, "The New Industrial Engineering: Information Technology and Business Process Redesign", in Sloan Management Review, Summer 1990, pp. 11-27. 